ARTICLE

https://doi.org/10.1038/s41467-019-11419-y

\title{
Facile access to nitroarenes and nitroheteroarenes using N-nitrosaccharin
}

Roxan Calvo ${ }^{1}$, Kun Zhang ${ }^{1}$, Alessandro Passera (iD ${ }^{1}$ \& Dmitry Katayev (iD ${ }^{1}$

Nitroaromatics and nitroheteroaromatics serve as key building blocks and intermediates in synthesis, and form the core scaffold of a vast number of materials, dyes, explosives, agrochemicals and pharmaceuticals. However, their synthesis relies on harsh methodologies involving excess mineral acids, which present a number of critical drawbacks in terms of functional group compatibility and environmental impact. Modern, alternative strategies still suffer from significant limitations in terms of practicality, and a general protocol amenable to the direct $\mathrm{C}-\mathrm{H}$ functionalization of a broad range of aromatics has remained elusive. Herein we introduce a bench-stable, inexpensive, easy to synthesize and recyclable nitrating reagent based on saccharin. This reagent acts as a controllable source of the nitronium ion, allowing mild and practical nitration of both arenes and heteroarenes displaying an exceptional functional group tolerance.

\footnotetext{
${ }^{1}$ Department of Chemistry and Applied Biosciences, ETH Zürich, Vladimir-Prelog-Weg 2, 8093 Zürich, Switzerland. Correspondence and requests for materials should be addressed to D.K. (email: katayev@inorg.chem.ethz.ch)
} 
E lectrophilic aromatic nitration is arguably one of the most extensively studied transformations in organic synthesis. The reaction has played a crucial role in our understanding of fundamental concepts underlying the reactivity of aromatics and has become an integral part of any undergraduate curricu$\operatorname{lum}^{1}$. Furthermore, nitroaromatics have become an essential class of compounds serving as key building blocks and versatile intermediates in organic synthesis and in the preparation of various industrial products ${ }^{2}$. These compounds serve as precursors to amines, hydroxylamines, aldehydes, carboxylic acids, isocyanates and various heterocycles, and are starting materials in the nitro-aldol and Michael reactions, as well as in various cycloadditions ${ }^{3}$. In an industrial context, nitrobenzene is an essential intermediate in the synthesis of aniline ${ }^{4}$, while nitro (hetero)aromatic compounds are important precursors in the synthesis of azo dyes, explosives, and materials ${ }^{2,4}$.

Despite the significance of electrophilic aromatic nitration and the value of nitroaromatic compounds, a mild and practical approach towards electrophilic aromatic nitration remains a challenge for synthetic chemists. To this day, the so called 'mixed acid' approach remains the fundamental process for the production of nitroaromatics on both laboratory and industrial scales $^{5,6}$. This methodology utilizes a mixture of nitric acid $\left(\mathrm{HNO}_{3}\right)$ and sulfuric acid $\left(\mathrm{H}_{2} \mathrm{SO}_{4}\right)$ as a solvent and source of the active electrophilic nitronium $\left(\mathrm{NO}_{2}{ }^{+}\right)$species ${ }^{7-9}$, and it is not surprising that this harsh methodology suffers from several critical drawbacks (Fig. 1a). Crucial issues include the poor regioselectivity and functional group tolerance of the protocol, as it is clearly unamenable to acid-sensitive functional groups, and side products resulting from oxidation or hydrolysis are often obtained. Furthermore, nitrogen oxides $\left(\mathrm{NO}_{x}\right)$ are generated along with superstoichiometric amounts of acidic waste, which both presents an environmental hazard and complicates isolation of the desired products?

While other classical electrophilic nitrating reagents, including acyl nitrates, nitryl halides, or nitronium salts circumvent the use of excess quantities of mineral acid, these reactions typically require harsh, and in many cases strictly anhydrous conditions, while some of these reagents are further susceptible to thermal decomposition ${ }^{9}$ (Fig. 1a). Various nitrate salts have been investigated in recent years as alternative nitrating agents, however generate stoichiometric amounts of metal waste ${ }^{10}$. Modern regiospecific nitration methodologies include ipso-nitration of prefunctionalized arenes ${ }^{10-12}$ and chelation-assisted nitration using transition metal catalysis ${ }^{13}$ and alternatively, aryl azides ${ }^{14}$, and primary amines ${ }^{15}$ can be oxidized to the corresponding nitro compounds (Fig. 1a). While tert-butyl nitrite has been investigated as an organic $\mathrm{NO}_{2}$ source in recent years, a general protocol for the nitration of broad classes of arenes using this reagent is still lacking ${ }^{16,17}$.

A mild and practical approach towards the nitration of a diverse range of arenes that does not require prefunctionalized a

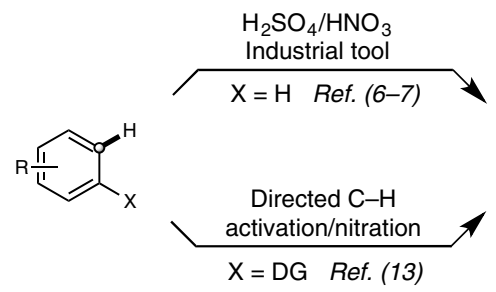

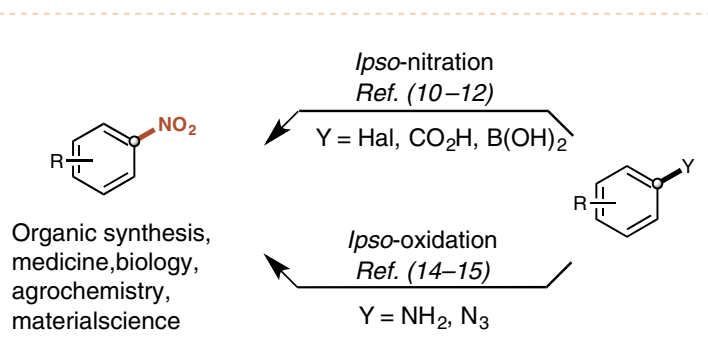

materialscience

$\begin{array}{lll}\text { - Harsh reaction conditions }(6-7,14) & \text { - Formation of side-products (6-7) Prefunctionalized starting materials (10-15) } \\ \text { - Poor functional group tolerance (6-7) } & \text { - Superstoichiometric acidic waste (6-7) - Stoichimetric metal waste (10-15) }\end{array}$

b<smiles>O=C1CCCN1[N+](=O)[O-]</smiles>

1<smiles>O=C1CCC(=O)N1[N+](=O)[O-]</smiles>
2<smiles>O=C1c2ccccc2C(=O)N1[N+](=O)[O-]</smiles>

3

Coburn \& Ungnade $(1965,1)$, Kauffmann \& Burger $(1954,2$ and 3): Compound synthesis reported, but reactivity unexplored.

This work (2019): Preparation, characterization and use as nitrating reagents in organic synthesis.

C<smiles>O=C(NN1C(=O)c2ccccc2S1(=O)=O)O[C@@H]([Pb])C(=O)O</smiles>

\section{Reagent}

- Bench-stable reagent

- Can be handled under air

- Cheap, one-step synthesis

- Recylable starting material

Nitration of arenes

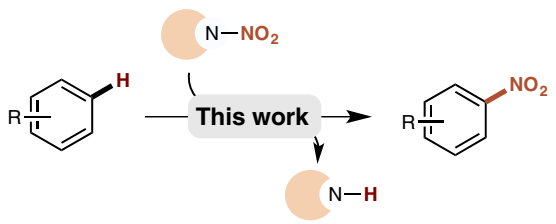

- Mild, neutral reaction conditions

- Excellent functional group tolerance

- High chemical efficiency

- No formation of unwanted side-products

- Only recoverable saccharin as by-product

- Scalable methodology

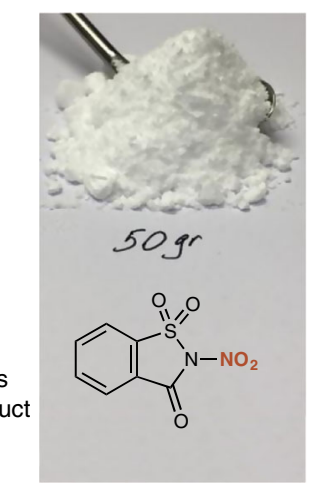

Fig. 1 Development of nitrating reagents. a Current methods to access nitroarenes. $\mathbf{b}$ Synthesis of a series of $\mathrm{N}-\mathrm{NO}_{2}$ heterocyclic compounds based on pyrrolidinone (1), succinimide (2), phthalimide (3), and saccharin (4) structures. c Our synthesis of reagent $\mathbf{4}$ and its application in the nitration of arenes 
starting materials remains in high demand at both an academic and industrial level. We speculated that the development of a nitrating reagent based on a tunable organic scaffold could offer a versatile approach towards the realization of such a process.

While the application of various $N$-nitramine-based reagents in electrophilic nitration of arenes has been investigated in the last century, these protocols suffer from high-moisture sensitivity, and the use of air-sensitive Lewis acid catalysts ${ }^{9,18}$. Nevertheless, these studies demonstrate the potential of such $\mathrm{R}_{2} \mathrm{~N}-\mathrm{NO}_{2}$ reagents to act as viable nitrating agents. Herein we present a mild and acid-free methodology for the electrophilic nitration of a diverse range of arenes and heteroarenes displaying an exceptional functional group tolerance. The reaction is enabled by $\mathbf{4}$, an easily accessible, inexpensive and recyclable reagent that is a bench-stable and convenient source of the $\mathrm{NO}_{2}$ group (Fig. 1c).

\section{Results}

Reaction development. We commenced by evaluating the reactivity of a series of $\mathrm{R}_{2} \mathrm{~N}-\mathrm{NO}_{2}$ heterocyclic compounds based on pyrrolidinone $(\mathbf{1})^{19}$, succinimide $(2)^{20}$, phthalimide $(\mathbf{3})^{20}$, and saccharin (4) core structures. While the application of $\mathbf{2}$ in aromatic nitration under photolysis has been investigated, the reagent demonstrated poor reactivity ${ }^{21}$ and likewise, we did not observe nitration of benzene using 2 during our initial reaction screening (Supplementary Table 2). However, we were pleased to observe that the nitration of benzene proceeded in $75 \%$ yield using reagent $4 \mathbf{a}$ in slight excess in acetonitrile at $85^{\circ} \mathrm{C}$ (Supplementary Table 3). Although the synthesis of $4 \mathbf{a}$ from saccharin has been reported using either unstable $\mathrm{NO}_{2} \mathrm{BF}_{4}$ or gaseous $\mathrm{N}_{2} \mathrm{O}_{5}$, with rudimentary characterization, its application as a nitrating reagent has to the best of our knowledge never been explored 22,23 . We pursued a practical approach towards $\mathbf{4 a}$, and achieved its synthesis on a $50 \mathrm{~g}$ scale in $95 \%$ yield from saccharin using a combination of fuming nitric acid and acetic anhydride (Fig. 1c). Structures of both reagents $\mathbf{4 a}$ and $\mathbf{4 b}$ have been confirmed by single crystal X-ray diffraction (Supplementary Tables 5 and 6). Characterization by differential scanning calorimetry and thermal gravimetric analysis revealed 4 a to be stable until $173{ }^{\circ} \mathrm{C}$ whereby a rapid exothermal decomposition was observed, accompanied by a mass loss of $87 \%$ (Supplementary Fig. 2).

Further screening on the nitration of benzene using $4 \mathrm{a}$ revealed the beneficial effects of fluorinated alcoholic solvents on the reaction, and employing 1,1,1,3,3,3-hexafluoroisopropanol (HFIP) as a solvent at $55^{\circ} \mathrm{C}$ afforded nitrobenzene in $99 \%$ in $3 \mathrm{~h}$. Additionally, a careful screening of various Brønsted or Lewis acids (Supplementary Table 3) revealed that the reaction proceeded smoothly using $10 \mathrm{~mol} \%$ of magnesium perchlorate $\left[\mathrm{Mg}\left(\mathrm{ClO}_{4}\right)_{2}\right]$ in acetonitrile at $85^{\circ} \mathrm{C}$. With two methodologies in hand, we proceeded to explore the scope and functional group compatibility in the nitration of various small and medium-sized molecules (Fig. 2). HFIP proved to be suitably activating in almost all cases, and only for exceptionally challenging deactivated substrates was the $\left[\mathrm{Mg}\left(\mathrm{ClO}_{4}\right)_{2}\right]$ protocol employed.

Reaction scope. Monosubstituted arenes containing both electron-donating and electron-withdrawing groups (5-20) were successfully nitrated in excellent yields. Halides (6-9), alkyl (1011), and alkoxy-groups (12-13) were well tolerated, with the expected $o$ - and $p$-nitrated products obtained in yields above $90 \%$ in all cases (Fig. 2). Remarkably, the nitration of toluene resulted in a slight excess of the para-regioisomeric product, which is in stark contrast to the generally observed preference of $o$-nitrobenzene formation under mixed acid conditions or when using nitronium salts ${ }^{24,25}$. Likewise, the ratio of $p$ - to $o$-tert-butyl- nitrobenzene is substantially higher than the expected $\sim 4: 1$ ratio using mixed acid $(\mathbf{1 1})^{24}$.

Nitration of cyclopropylbenzene (14) proceeded smoothly, with no ring opening observed. The method proved amenable to sulfides (15), whereby none of the oxidized side products generally observed when using mixed acid were formed, as well as tertiary amines (16). In the case of $\mathbf{1 5}$ the use of $\left[\mathrm{Mg}\left(\mathrm{ClO}_{4}\right)_{2}\right]$ catalysis led to a noticeable increase in yield. Similarly [Mg $\left.\left(\mathrm{ClO}_{4}\right)_{2}\right]$ was employed in the nitration of deactivated trifluoromethylbenzene (17) and benzonitrile (18), furnishing the anticipated $o$ - and $m$-substituted products in good yields. The smooth nitration of benzonitrile under our conditions is noteworthy, as aryl nitriles are susceptible to hydrolysis under standard mixed acid conditions ${ }^{26}$. The nitration of methyl benzoate (19) and benzophenone (20) also proceeded smoothly without any hydrolysis of the ester or ketone moieties. Biphenyl underwent nitration selectively on one aromatic ring (21), while nitration of naphthalene (22) and anthracene (23) delivered only the expected isomers. The reaction proceeded well using various other di-and trisubstituted arenes containing both electrondonating and strongly withdrawing groups (24-31). Notably, the nitration proved to be compatible with aldehydes (25), carboxylic acids (26), phenols (26-27), and amides (32-33), as well as sulfoxides (34) and boronate esters (35). To our surprise, nitration of methyl 4-tert-butyl benzoate resulted in introduction of the nitro group ortho to the ester substituent (24) as the major regioisomeric product. While the nitration of boronate esters remains poorly explored in the literature ${ }^{27}$, nitration of boronic acids using nitric acid results in formation of the pararegioisomeric product in $70 \%$ yield $^{28}$. In contrast, we observed an almost 1:1 ratio of para to ortho products in the nitration of phenyl boronic acid pinacol ester 35 . This could be rationalized on the grounds of a stabilizing interaction between the reagent's oxygen atom and boron's empty p-orbital, directing nitration to the ortho position (vide infra, Fig. 4e).

Our protocol also proved applicable in the nitration of heteroarenes. While the nitration of 2,6-dichloro-and 2,6dimethylpyridine typically involves mixed acid at temperatures above $100^{\circ} \mathrm{C}^{29,30}$, we were pleased to observe the formation of $\mathbf{3 6}$ and 37 in acceptable yield using $\mathbf{4 a}$ under our Lewis acid catalyzed conditions. This protocol was also suitable in the nitration of substituted pyrimidines (38-39), while substituted furan (40) and thiophenes (41-42) were nitrated in good yields in HFIP.

In all cases, we were unable to observe polynitration under established conditions. To further demonstrate the applicability and recyclability of $\mathbf{4 a}$, the nitration of benzene in HFIP was performed on a $7.5 \mathrm{~g}$ scale with no decrease in yield, and both saccharin and HFIP were recovered in $97 \%$ and $90 \%$, respectively.

We subsequently investigated the application of our nitration protocol in late-stage functionalization. Nitroaromatics have in recent decades proven to be an important class of molecules for the preparation of biologically active substances, finding application as pesticides 31 , and as anticancer, antiparasitic and antitubercular agents, as well as antibiotics and tranquilizers ${ }^{32}$ and as such, we foresaw that our methodology could be of particular value in the context of medicinal and agrochemistry. To this end, a series of nitrated derivatives of known drugs, including ibuprofen (43), lidocaine (44), naproxen (45), clofibrate (46), phenytoin (47), and nimesulide (48) were synthesized in good to excellent yields, the latter furthermore demonstrating the protocol's tolerance to sulfonamides (Fig. 3). In addition, our protocol enabled the direct preparation of antibiotic Secnidazol $(49)^{33}$. A precursor to the Alzheimer's drug Aricept (50), the commonly used fragrant and intermediate in the synthesis of various pharmaceuticals ventraldehyde (51), and drug 


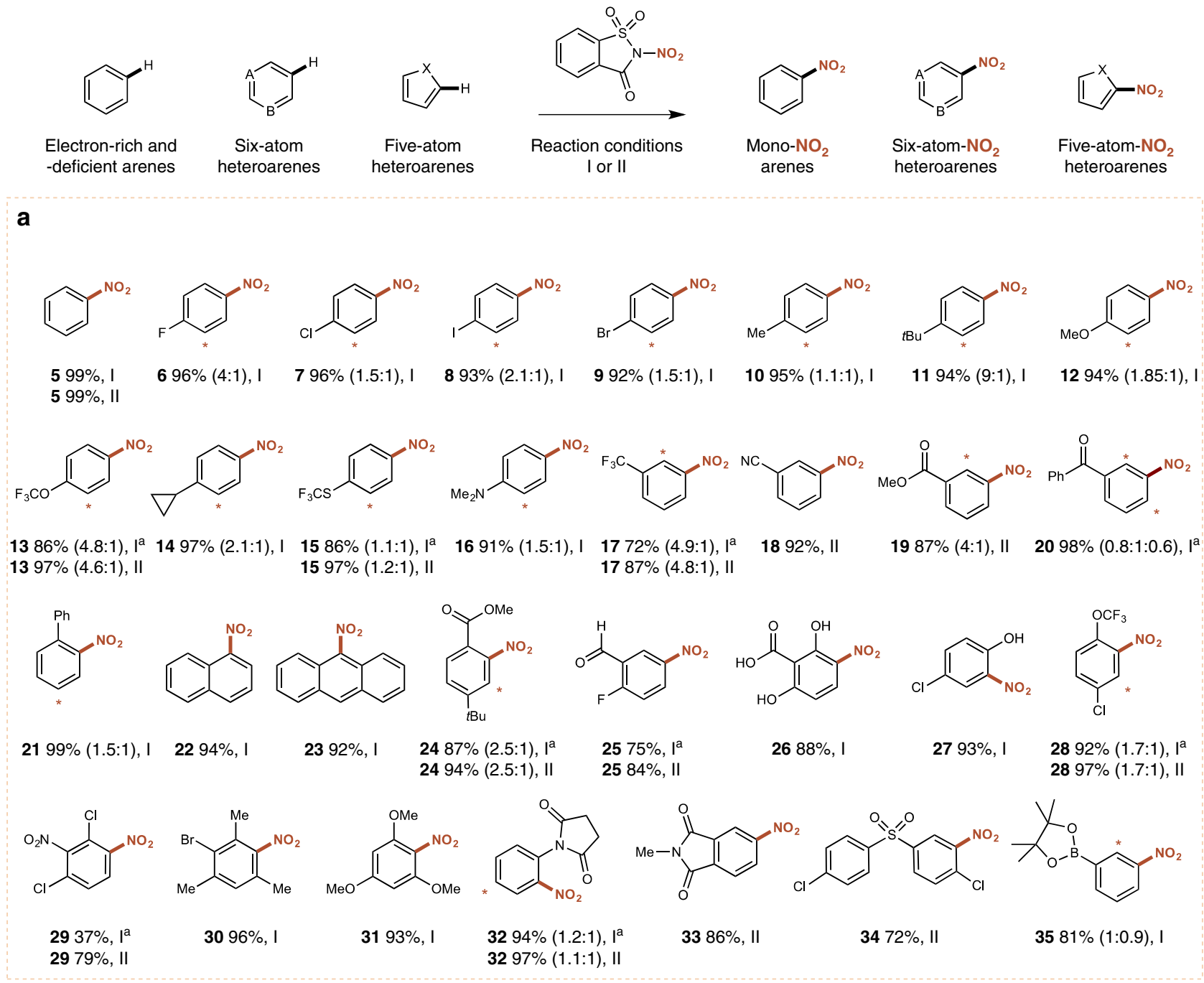

b<smiles>O=[N+]([O-])c1ccc(Cl)nc1Cl</smiles>

36 65\%, II<smiles>Cc1ccc([N+](=O)[O-])c([N+](=O)[O-])n1</smiles>

$3767 \%$, II<smiles>O=[N+]([O-])c1cnc(Cl)nc1Cl</smiles>

$3859 \%$, II<smiles>O=[N+]([O-])c1nc(Cl)nc(Cl)c1[N+](=O)[O-]</smiles>

$3956 \%$, II<smiles>NC(=O)c1ccc([N+](=O)[O-])o1</smiles>

$4077 \%$,<smiles>Cc1cc([N+](=O)[O-])sc1C</smiles>

$4182 \%, \mathrm{I}^{\mathrm{a}}$<smiles>O=C(c1ccc([N+](=O)[O-])s1)C1CC1</smiles>

$4284 \%$, l $^{\mathrm{a}}$

Fig. 2 Electrophilic nitration of arenes and five- and six-membered heteroarenes using 4a. Standard procedures: I (Hetero)arene (0.5 mmol), 4a $(0.65 \mathrm{mmol}), \mathrm{HFIP}(0.5 \mathrm{M}), 55^{\circ} \mathrm{C}, 3 \mathrm{~h}([\mathrm{a}], 19 \mathrm{~h})$; Il (Hetero)arene $(0.5 \mathrm{mmol}), \mathbf{4 a}(0.65 \mathrm{mmol}),\left[\mathrm{Mg}\left(\mathrm{ClO}_{4}\right)_{2}\right](10 \mathrm{~mol} \%), \mathrm{CH}_{3} \mathrm{CN}(0.5 \mathrm{M}), 85^{\circ} \mathrm{C}, 5 \mathrm{~h}$ ([a], $19 \mathrm{~h})$. Yields refer to the isolated product of a single regioisomer or a sum of separately isolated regioisomers. [*] The minor regioisomeric position is labeled. Scale up synthesis of $\mathbf{5}$ under conditions I (reaction run on $84.0 \mathrm{mmol}$ of benzene; yield of $\mathbf{5}$ is $97 \%$ ). a Nitration of small and medium-sized building blocks. b Nitration of heteroaromatic compounds

intermediate 52 all smoothly underwent nitration. Furthermore, a nitrated derivative of pesticide procymidone (53) was prepared, and the herbicide fluorodifen $(\mathbf{5 4})^{34}$ could be synthesized directly from the corresponding diphenyl ether in $88 \%$ yield and good regioselectivity. Our protocol was also successfully applied in the nitration of naturally occurring estrone (55), arbutin (56), vitamin E (57), nodihydrocapsaicin (58), and L-phenylalanine (59). To show the applicability of our protocol beyond pharmaceuticals and agrochemicals, nitrated derivatives of chiral building blocks binol (60) and [2,2] paracyclophane (61) were synthesized, thereby providing a convenient strategy for the development of chiral ligands for asymmetric catalysis. The reaction also proved suitable for the modification of organic materials, demonstrated through the nitration of a liquid crystalline material (62).

Mechanistic considerations. Despite arene nitration via electrophilic aromatic substitution being one of the oldest studied reactions, mechanistic aspects of the transformation are still being elucidated today ${ }^{1,35}$. In light of recent studies considering the effects of implicit solvent molecules on electrophilic nitration of arenes under acidic conditions ${ }^{36,37}$, we were motivated to gain mechanistic insight into the transfer of the $\mathrm{NO}_{2}$ group and the role of HFIP in facilitating this reaction. We commenced by performing the nitration of benzene in the presence of radical scavengers, and did not observe significant inhibition (Fig. 4a). 
<smiles>COC(=O)[C@H](C)c1ccc(CC(C)C)c([N+](=O)[O-])c1</smiles>

From ibuprofen anti-inflammatory $4389 \%(2.5: 1)$, l $^{\mathrm{a}}$<smiles>CS(=O)(=O)Nc1ccc([N+](=O)[O-])cc1Oc1ccc([N+](=O)[O-])cc1</smiles>

From nimesulide anti-inflammatory 48 99\% (3.3:1), I<smiles>CCN(CC)CC(=O)Nc1c([N+](=O)[O-])ccc([N+](=O)[O-])c1[N+](=O)[O-]</smiles>

From lidocaine anaesthetic, anti-arrhythmic $4471 \%, a^{\mathrm{a}}$<smiles>Cc1ncc([N+](=O)[O-])n1CC(C)O</smiles>

Secnidazole antibiotic $4944 \%$, II<smiles>COc1ccc2cc([C@H](C)C(=O)O)ccc2c1[N+](=O)[O-]</smiles>

From naproxen anti-inflammatory drug $4590 \%$, I $^{\mathrm{a}}$<smiles>CCOC(=O)C(C)(C)Oc1ccc(Cl)cc1[N+](=O)[O-]</smiles>

From clofibrate against cardiovascular disease 46 98\%, I<smiles></smiles>

From phenytoin anti-seizure 47 98\%, (7.6:4:1 p:o:m), ।<smiles>O=C(OCc1ccccc1)OCc1cn(-c2ccc([N+](=O)[O-])cc2)nc1C(F)(F)F</smiles>

Drug intermediate anti-cancer, antifungal 52 93\% (8.3:1), II<smiles>CC12CC1(C)C(=O)N(c1cc(Cl)cc(Cl)c1[N+](=O)[O-])C2=O</smiles>

From procymidone
pesticide pesticide
$\mathbf{5 3} 91 \%,\left.\right|^{\mathrm{a}}$

Fluorodifen, peroxidizing herbicide 54 88\% (15:1), I $^{\mathrm{a}}$<smiles>COc1cc2c(c([N+](=O)[O-])c1[N+](=O)[O-])OC(C)(CCC[C@@H](C)CCC[C@H](C)CCCC(C)C)CC2</smiles>
From $\gamma$-vitaminE antioxidants, $5775 \%$, I<smiles>COc1ccc2ccccc2c1-c1c(OC)c([N+](=O)[O-])cc2ccccc12</smiles>

From binol derivative $6064 \%$, I

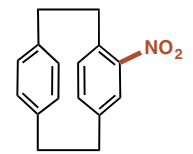

From [2,2] paracyclophane $6194 \%$, II
Aricept precurs Anti-Alzheimer's<smiles>COc1cc(C=O)cc([N+](=O)[O-])c1OC</smiles>

Methylvaniline Flavorant (coffee/chocolate) 51 91\%, I

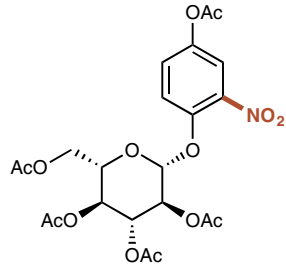

From arbutin $5674 \%$, II

From estrone, hormone drug 55 91\% (6:1), I

ug<smiles>Cc1ccc2c(c1[N+](=O)[O-])CCC1C2CC[C@]2(N)C(=O)CCC12</smiles><smiles>CCCCCCCCC(=O)NCc1cc(OC)c(O)c([N+](=O)[O-])c1</smiles>

From nordihydrocapsaicin $5894 \%$, I

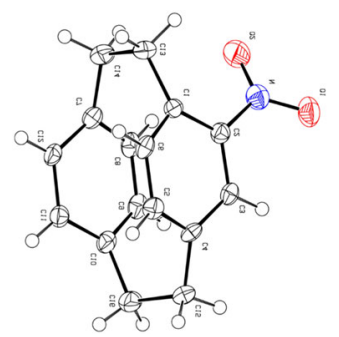<smiles>N[C@@H](Cc1ccc([N+](=O)[O-])cc1)C(=O)O</smiles>

From L-phenylalanine 59 64\%,(3.8:1), I

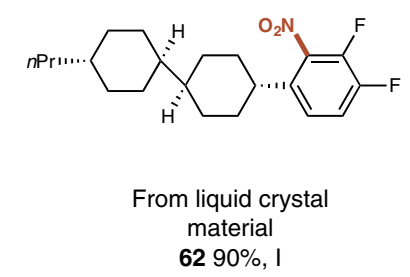

Fig. 3 Direct electrophilic nitration of complex molecules and biorelevant compounds using $\mathbf{4 a}$. Standard procedures: I (Hetero)arene (0.5 mmol), 4 a $(0.65 \mathrm{mmol}), \mathrm{HFIP}(0.5 \mathrm{M}), 55^{\circ} \mathrm{C}, 3 \mathrm{~h}([\mathrm{a}], 19 \mathrm{~h})$; II (Hetero)arene $(0.5 \mathrm{mmol}), \mathbf{4 a}(0.65 \mathrm{mmol}),\left[\mathrm{Mg}\left(\mathrm{ClO}_{4}\right)_{2}\right](10 \mathrm{~mol} \%), \mathrm{CH} \mathrm{CN} \mathrm{C}(0.5 \mathrm{M}), 85^{\circ} \mathrm{C}, 5 \mathrm{~h}([\mathrm{a}]$, $19 \mathrm{~h}$ ). Yields refer to the isolated product of a single regioisomer or a sum of separately isolated regioisomers. $\left.{ }^{\star}\right]$ The minor regioisomeric position is labeled

An intermolecular competition experiment with a secondary isotope effect of 0.89 is consistent with the known fact that $\mathrm{C}-\mathrm{N}$ bond formation is the rate-determining step in electrophilic aromatic substitution (Fig. 4b) ${ }^{38}$. Subsequently, a Hammett study revealed a small negative $\rho$-value of -0.66 (Fig. $4 \mathrm{c}$ ). In the presence of reagent $4 \mathbf{a}$, the half-life $\left(t_{1 / 2}\right)$ of the first order reaction on the substrate was $\sim 92$ min (Supplementary Fig. 9), while usingreagent $\mathbf{4 b}$ the reaction rate drastically increased, with a $t_{1 / 2}$ of $\sim 8$ min (Supplementary Fig. 10).

Owing to its unique properties, HFIP has in recent years proven to be a versatile solvent and additive with broad applications ${ }^{39-41}$. While HFIP may promote nitration due to its cation stabilization ability, we postulated that its strong hydrogen bonding capacity may also activate $\mathbf{4 a}$.
To further distinguish between a polar electrophilic process or radical mechanism, and to understand the role of HFIP, we turned to density functional theory (DFT) studies. Prior to nitronium transfer we did not observe formation of a $\pi$ complex, but the $\mathrm{NO}_{2}$ group of $\mathbf{4 a}$ was found to interact with HFIP via a hydrogen bond (Supplementary Fig. 15). The reaction then proceeds with a concerted and strongly asynchronous mechanism (Fig. 4e) whereby the $\mathrm{C}-\mathrm{N}$ bond formation was found to be the rate-determining step (Fig. $4 \mathrm{~d}$ ), in agreement with the first-order reaction in benzene (Supplementary Fig. 9) and the observed KIE (Fig. 4b). In this transformation, the $\sigma$ complex was not located as a discreet intermediate, although it is observed in the reaction profile and is rapidly followed by $\mathrm{H}^{+}$elimination assisted by saccharin's sulfoxide group (Fig. 4d, e) ${ }^{36,42}$. 
a

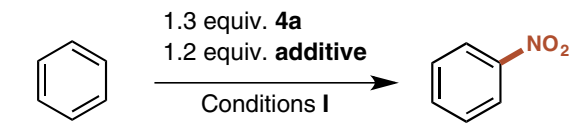

1.4-Dinitrobenzene

Allyl ether

Benzoquinone

Styrene b

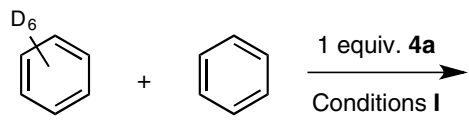

Excess<smiles>O=[N+]([O-])c1ccccc1</smiles>

$k_{\mathrm{H}} / k_{\mathrm{D}} \mathrm{KIE}=0.89$
C
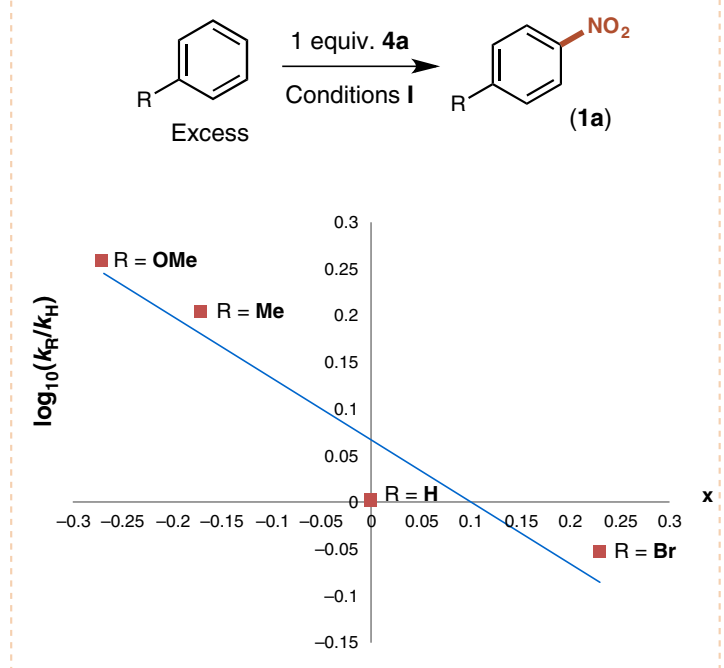

d

\section{d}

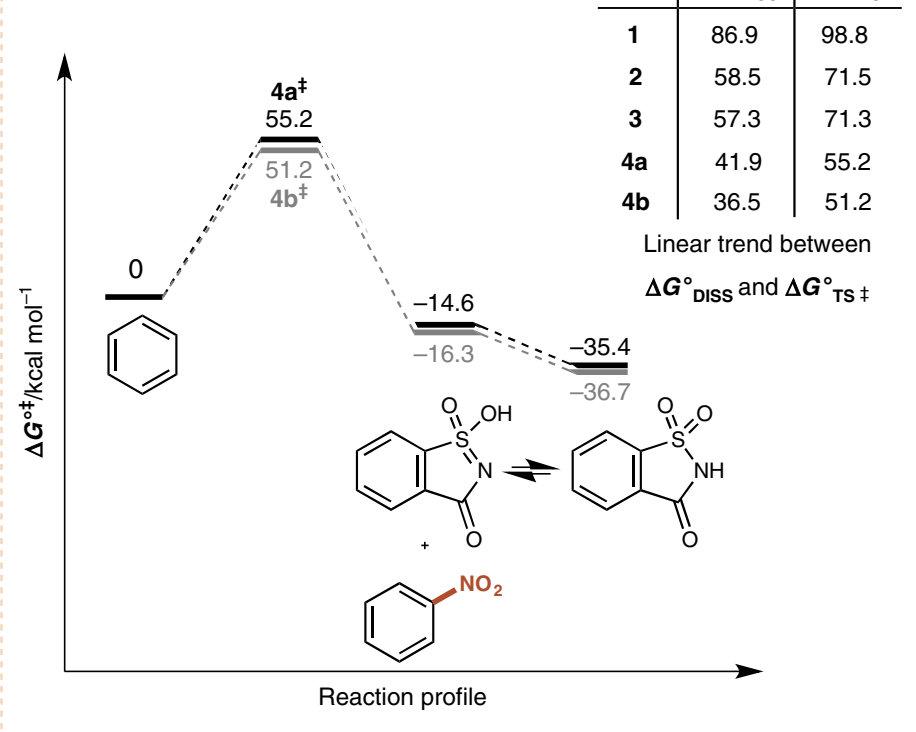

e
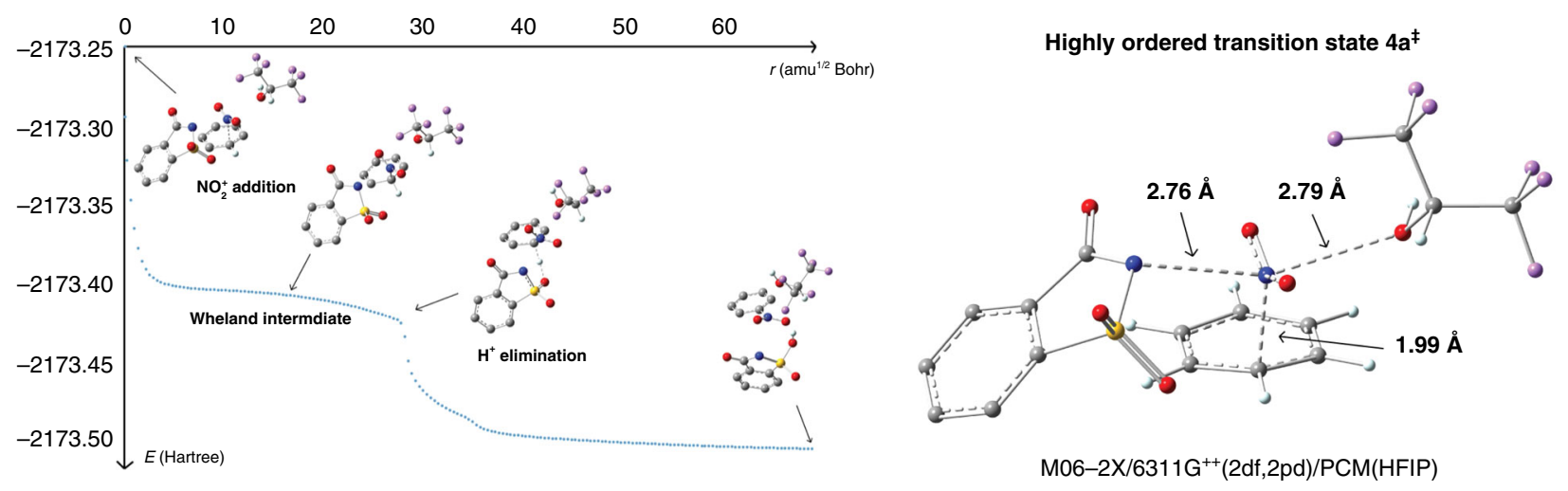

Fig. 4 Mechanistic studies into the nitration of arenes using $\mathbf{4}$ and procedure $\mathbf{I}$. a Radical trapping experiments. $\mathbf{b}$ Kinetic isotope effect by intermolecular competition experiment. $\mathbf{c}$ Hammett study. $\mathbf{d}$ Gibbs-free energy profile for nitration of benzene using $\mathbf{4 a}$ and $\mathbf{4 b}$. e Transition state of nitronium addition to benzene and intrinsic reaction coordinate for nitration of benzene after rate-determining step

The reagent's activity as a controllable source of the nitronium ion is elucidated when considering the high level of organization in the transition state, where HFIP (O atom) interacts with the $\mathrm{NO}_{2}$ group ( $\mathrm{N}$ atom, $2.79 \AA$ ), assisting the cleavage of the $\mathrm{N}-\mathrm{N}$ bond and the concomitant addition of the nitronium species to the aromatic ring (Fig. 4e). It is this highly ordered transition state that enables delivery of the nitronium ion from $\mathbf{4 a}$ in a controlled fashion.

Curious about the high para:ortho ratio in the nitration of tertbutyl-benzene, we calculated the selectivity according to the transition state distribution. A good match was found between the experimental and calculated ratios, and the high para selectivity can be explained by steric hindrance in the transition state, whereby 4a shields one ortho position, and the HFIP molecule the other (Supplementary Fig. 22). This steric hindrance likewise also accounts for the introduction of the nitro group ortho to the ester substituent in $\mathbf{2 4}$.

Finally, a trend was found between the activation Gibbs free energy $\left(\Delta G^{\circ \ddagger}\right)$ and the dissociation Gibbs free energy for the heterolytic cleavage of the $\mathrm{N}-\mathrm{N}$ bond ( $\left.\Delta G^{\circ}{ }_{\text {DISS }}\right)$ for the series of nitrating reagents 1-4. The findings are in agreement with the drastically increased rate of reaction for $\mathbf{4 b}$ compared to $\mathbf{4 a}$ 
(Supplementary Figs. 9 and 10), and also allows prediction of the reactivity of 1-4 (Fig. 4d).

\section{Discussion}

Using the bench-stable and recyclable electrophilic nitrating reagent $4 \mathbf{a}$, we have developed a general protocol for the direct synthesis of a broad range of nitroarenes and nitroheteroarenes demonstrating an exceptional functional group tolerance. Furthermore, our method was applicable to the late-stage $\mathrm{C}-\mathrm{H}$ functionalization of a range of complex molecules. Mechanistic studies strongly support a classical electrophilic aromatic nitration, which was found to proceed through a unique and highly ordered transition state. As such, our reagent behaves as a controllable source of the nitronium ion, enabling such a mild and functional group tolerant reaction.

\section{Methods}

General procedure I for the nitration of (hetero)arenes. An oven-dried $25 \mathrm{ml}$ micro-vial was charged on the benchtop with a magnetic pTFE-coated stirbar and $4 a(148 \mathrm{mg}, 0.65 \mathrm{mmol}, 1.3$ equiv.). The vial was sealed and the atmosphere was cycled $3 \mathrm{x}$ with $\mathrm{Ar} / \mathrm{vac}$. (Hetero)arene substrate $(0.5 \mathrm{mmol}, 1.0$ equiv.) in HFIP $(1 \mathrm{ml})$ was added by plastic syringe and the reaction mixture was heated at $55^{\circ} \mathrm{C}$ with vigorous stirring for $3 \mathrm{~h}$. After cooling to room temperature, the solvent was removed under reduced pressure, and the product was purified by flash column chromatography $\left(\mathrm{SiO}_{2}\right.$, ethyl acetate/ $n$-hexange gradient).

General procedure II for the nitration of (hetero)arenes. An oven-dried $25 \mathrm{ml}$ micro-vial was charged on the benchtop with a magnetic pTFE-coated stirbar, 4a (148 mg, $0.65 \mathrm{mmol}, 1.3$ equiv.) and $\left[\mathrm{Mg}\left(\mathrm{ClO}_{4}\right)_{2}\right](11.2 \mathrm{mg}, 0.05 \mathrm{mmol}, 10 \mathrm{~mol} \%)$. The vial was sealed and the atmosphere was cycled $3 \mathrm{x}$ with $\mathrm{Ar} / \mathrm{vac}$. (Hetero)arene substrate $(0.5 \mathrm{mmol}, 1.0$ equiv.) in $\mathrm{MeCN}(1 \mathrm{ml})$ was added with a plastic syringe, and the reaction mixture was heated at $85^{\circ} \mathrm{C}$ with vigorous stirring for $5 \mathrm{~h}$. After cooling to room temperature, the solvent was removed under reduced pressure, and the product was purified by flash column chromatography $\left(\mathrm{SiO}_{2}\right.$, ethyl acetate/ $n$-hexane gradient).

\section{Data availability}

The authors declare that the data supporting the findings of this study, including synthetic procedures, NMR spectra, characterization for all new compounds and further details of computational studies, are available in the article and its Supplementary Information, or from the corresponding author upon reasonable request. The X-ray crystallographic coordinates for structures of $\mathbf{4 a}, \mathbf{4 b}, \mathbf{5 4}$, and $\mathbf{6 1}$ have been deposited at the Cambridge Crystallographic Data Center (CCDC), under deposition numbers CCDC-1903469, CCDC-1903468, CCDC-1903470, and CCDC-1456828, respectively. These data can be obtained free of charge from The Cambridge Crystallographic Data Center via https://www.ccdc.cam.ac.uk/.

Received: 5 June 2019 Accepted: 13 July 2019

Published online: 30 July 2019

\section{References}

1. Esteves, P. M. et al. Unified mechanistic concept of electrophilic aromatic nitration: convergence of computational results and experimental data. J. Am. Chem. Soc. 125, 4836-4849 (2003).

2. Booth, G. Ullmann's Encyclopedia of Industrial Chemistry (Wiley, New York, 2000).

3. Ono, N. The Nitro Group in Organic Synthesis. (John Wiley \& Sons, Inc., New York, 2001).

4. Kulkarni, A. A. Continuous flow nitration in miniaturized devices. Beilstein J. Org. Chem. 10, 405-424 (2014).

5. Greish, A. Nitration of aromatic hydrocarbons over heterogenous catalysts. Rus. Chem. J. 48, 92-104 (2004).

6. Koskin, A. P., Mishakov, I. V. \& Vedyagin, A. A. In search of efficient catalysts and appropriate reaction conditions for gas phase nitration of benzene. Resour. Technol. 2, 118-125 (2016).

7. Hughes, E. D., Ingold, C. K. \& Reed, R. I. Kinetics of aromatic nitration: the nitronium ion. Nature 158, 448-449 (1946).

8. Halberstadt, E. S., Hughes, E. D. \& Ingold, C. K. Kinetics of aromatic nitration: the nitracidium ion. Nature 158, 514-514 (1946)

9. Olah, G. A., Malhotra, R. \& Narang, S. C. Nitration: Methods and Mechanisms. (VCH Publishers, Inc, New York, 1989).
10. Yan, G. \& Yang, M. Recent advances in the synthesis of aromatic nitro compounds. Org. Biomol. Chem. 11, 2554-2566 (2013).

11. Prakash, G. K. S. et al. Ipso-nitration of arylboronic acids with chlorotrimethylsilane-nitrate salts. Org. Lett. 6, 2205-2207 (2004).

12. Fors, B. P. \& Buchwald, S. L. Pd-Catalyzed conversion of aryl chlorides, triflates, and nonaflates to nitroaromatics. J. Am. Chem. Soc. 131, 12898-12899 (2009).

13. Song, L. -R., Fan, Z. \& Zhang, A. Recent advances in transition metalcatalyzed C( $\left.\mathrm{sp}^{2}\right)-\mathrm{H}$ nitration. Org. Biomol. Chem. 17, 1351-1361 (2019).

14. Rozen, S. \& Carmeli, M. From azides to nitro compounds in a few seconds using HOF. $\mathrm{CH}_{3}$ CN. J. Am. Chem. Soc. 125, 8118-8119 (2003).

15. Reddy, K. R., Maheswari, C. U., Venkateshwar, M. \& Kantam, M. L. Selective oxidation of aromatic amines to nitro derivatives using potassium iodidetert-butyl hydroperoxide catalytic system. Adv. Synth. Catal. 351, 93-96 (2009).

16. Kilpatrick, B., Heller, M. \& Arns, S. Chemoselective nitration of aromatic sulfonamides with tert-butyl nitrite. Chem. Commun. 49, 514-516 (2013).

17. Wu, X. -F., Schranck, J., Neumann, H. \& Beller, M. Convenient and mild synthesis of nitroarenes by metal-free nitration of arylboronic acids. Chem. Commun. 47, 12462-12463 (2011).

18. Olah, G. A., Narang, S. C., Olah, J. A. \& Lammertsma, K. Recent aspects of nitration: new preparative methods and mechanistic studies (A Review). Proc. Natl Acad. Sci. 79, 4487-4494 (1982).

19. Coburn, M. D. \& Ungnade, H. E. Synthesis and structure of the Nnitropyrrolidinones. J. Heterocycl. Chem. 2, 308-309 (1965).

20. Kauffman, H. F. \& Burger, A. N-Nitrosuccinimide and N-nitrophthalimide. J. Org. Chem. 19, 1662-1670 (1954).

21. Calvert, J., Eberson, L., Hartshorn, M. P. \& Svensson, J. O. Succinimidylation and nitration of aromatic compounds by photolysis with $\mathrm{N}$-nitrosuccinimide. J. Chem. Soc. Perkin Trans. 2, 645-652 (1995).

22. Kozlova, I. K., Luk'yanov, O. A. \& Tartakovskii, V. A. Chemistry of nitro imides. Bull. Acad. Sci. USSR Div. Chem. Sci. 30, 1712-1714 (1981).

23. Runge, J. \& Treibs, W. Die Darstellung von N-Nitroacylalkylamiden und -diacylimiden mit Hilfe von Distickstoffpentoxyd. J. für. Prakt. Chem. 15, 223-227 (2005)

24. Fulkrod, J. E. A laboratory study of strike and inductive effects. J. Chem. Educ. 51, 115 (1974).

25. Nieves-Quinones, Y. \& Singleton, D. A. Dynamics and the regiochemistry of nitration of toluene. J. Am. Chem. Soc. 138, 15167-15176 (2016).

26. Hammond, G. S., Douglas, K. J., Hammond, G. S. \& Douglas, K. J. Aromatic nitration. III. The ortho to para ratio in nitration of benzonitrile. J. Am. Chem. Soc. 81, 1184-1187 (1959).

27. Cummings, W. M., Cox, C. H. \& Snyder, H. R. Arylboronic acids. Medium size ring containing boronic ester groups. J. Org. Chem. 34, 1669-1674 (1969).

28. Ainley, A. D. \& Challenger, F. CCLXXX.-Studies of the boron-carbon linkage. Part I. The oxidation and nitration of phenylboric acid. J. Chem. Soc. Perkin Trans. 1, 2171-2180 (1930).

29. Steinmetz, G. \& Thiele, K. 2,6-dichloro-3-nitro-pyridine. Patent number US3809695A, 7 May 1974

30. Zohuri, G. H., Seyedi, S. M., Sandaroos, R., Damavandi, S. \& Mohammadi, A. novel late transition metal catalysts based on iron: synthesis, structures and ethylene polymerization. Catal. Lett. 140, 160-166 (2010).

31. Ju, K. S. \& Parales, R. E. Nitroaromatic compounds, from synthesis to biodegradation. Microbiol. Mol. Biol. Rev. 74, 250-272 (2010).

32. Nepali, K., Lee, H. -Y. \& Liou, J. -P. Nitro-group-containing drugs. J. Med. Chem. 62, 2851-2893 (2019).

33. Gillis, J. C. \& Wiseman, L. R. Secnidazole. Secnidazole. A review of its antimicrobial activity, pharmacokinetic properties and therapeutic use in the management of protozoal infections and bacterial vaginosis. Drugs 51, 621-638 (1996).

34. Böger, P. \& Wakabayashi, K. Peroxidizing Herbicides. (Springer, Berlin, Heidelberg, 1999).

35. Galabov, B., Nalbantova, D., Schleyer, P., von, R. \& Schaefer, H. F. Electrophilic aromatic substitution: new insights into an old class of reactions. Acc. Chem. Res. 49, 1191-1199 (2016).

36. Koleva, G. et al. An experimentally established key intermediate in benzene nitration with mixed acid. Angew. Chem. Int. Ed. 54, 14123-14127 (2015).

37. Lu, L., Liu, H. \& Hua, R. $\mathrm{HNO}_{3}$ /HFIP: a nitrating system for arenes with direct observation of $\pi$-complex intermediates. Org. Lett. 20, 3197-3201 (2018).

38. Smith, M. \& March, J. March's Advanced Organic Chemistry: Reactions, Mechanisms, and Structure. (John Wiley \& Sons, Inc., Hoboken, New Jersey, 2007).

39. Colomer, I., Chamberlain, A. E. R., Haughey, M. B. \& Donohoe, T. J. Hexafluoroisopropanol as a highly versatile solvent. Nat. Rev. Chem. 1, 88 (2017).

40. D'Amato, E. M., Börgel, J. \& Ritter, T. Aromatic C-H amination in hexafluoroisopropanol. Chem. Sci. 10, 2424-2428 (2019). 
41. Börgel, J., Tanwar, L., Berger, F. \& Ritter, T. Late-stage aromatic C-H oxygenation. J. Am. Chem. Soc. 140, 16026-16031 (2018).

42. Galabov, B. et al. Arenium ions are not obligatory intermediates in electrophilic aromatic substitution. Proc. Natl Acad. Sci. USA 111, 10067-10072 (2014).

\section{Acknowledgements}

We thank the ETH transfer office for support in filling two patent applications on this work (application numbers are EP18 20295.6 and EP18 202 99.6), where D.K., K.Z. and R.C. are listed as inventors. Dr. Phil Liebing and Ewa Pietrasiak are acknowledged for obtaining all X-ray crystallographic data. D.K. and R.C. acknowledge the Swiss National Science Foundation (SNSF, PZ00P2_168043) and Z.K. acknowledges the Shanghai Friend Biologic Technology Company for the financial supports of this research. Generous continued support by the ETH Zürich is acknowledged.

\section{Author contributions}

D.K. conceived the project and performed initial reaction optimization; D.K. and R.C carried out the experiments; K.Z. designed and prepared nitrating reagents; A.P. performed computational studies; D.K. and R.C. wrote the manuscript.

\section{Additional information}

Supplementary Information accompanies this paper at https://doi.org/10.1038/s41467019-11419-y.

Competing interests: The authors declare no competing interests.

Reprints and permission information is available online at http://npg.nature.com/ reprintsandpermissions/

Peer review information: Nature Communications thanks anonymous reviewer(s) for their contribution to the peer review of this work. Peer reviewer reports are available.

Publisher's note: Springer Nature remains neutral with regard to jurisdictional claims in published maps and institutional affiliations.

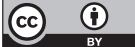

Open Access This article is licensed under a Creative Commons Attribution 4.0 International License, which permits use, sharing, adaptation, distribution and reproduction in any medium or format, as long as you give appropriate credit to the original author(s) and the source, provide a link to the Creative Commons license, and indicate if changes were made. The images or other third party material in this article are included in the article's Creative Commons license, unless indicated otherwise in a credit line to the material. If material is not included in the article's Creative Commons license and your intended use is not permitted by statutory regulation or exceeds the permitted use, you will need to obtain permission directly from the copyright holder. To view a copy of this license, visit http://creativecommons.org/ licenses/by/4.0/.

(C) The Author(s) 2019 